\title{
Pancreatic Cancer: Current Options for Diagnosis, Staging and Therapeutic Management
}

\author{
Werner Hartwig Markus W. Büchler \\ Department of General, Visceral and Transplantation Surgery, University of Heidelberg, \\ Heidelberg, Germany
}

\section{Key Message}

An interdisciplinary, multimodal approach to therapy is critical for improving the outcomes of patients with pancreatic cancer.

\section{Practical Implications}

Cross-sectional imaging techniques (such as contrast-enhanced multidetector computed tomography) are useful for assessing tumor resectability. For localized, non-metastatic, resectable tumors, the necessity of preoperative biopsies remains controversial. Important prognostic parameters are tumor size, invasion of surrounding tissue, lymph node metastasis and distant metastasis. Various classification systems based on the TNM system have been used for tumor staging and prognosis. The presence of distant metastases is regarded as non-resectable disease, requiring chemotherapy as first treatment. The definition of borderline resectable tumors is still under debate, although a recent definition has been provided by an expert consensus statement. Standard lymphadenectomy is the recommended procedure in pancreatoduodenectomy, based upon the guidelines of the International Study Group of Pancreatic Surgery (ISGPS). Adjuvant chemotherapy is applied in generally all cases of pancreatic ductal adenocarcinoma following macroscopic complete tumor resection. The benefits of adjuvant chemoradiotherapy or immunochemoradiotherapy, or neoadjuvant therapy, however, remain a matter of controversy. For palliative treatment gemcitabine monotherapy is widely used; the FOLFIRINOX protocol provides an alternative for a minority of patients. 
Hartwig et al.: Pancreatic Cancer: Current Options for Diagnosis, Staging and Therapeutic Management

\title{
Key Words
}

Diagnostics · Multimodal therapy · Palliative therapy · Pancreatic ductal adenocarcinoma . Surgery

\begin{abstract}
Background: Pancreatic cancer is characterized by frequently delayed diagnosis and aggressive tumor growth which hampers most of the current treatment modalities. This review aims to summarize the available evidence about the diagnostic and therapeutic aspects of resectable and non-resectable pancreatic cancer therapy. Summary: Embedded in the concept of multimodal therapy, surgery plays the central role in the treatment of pancreatic cancer. With advantageous tumor characteristics and complete tumor resection as the most relevant positive prognostic factors, the detection of premalignant or early invasive lesions combined with safe and oncologic adequate surgery is the major therapeutic aim. Most pancreatic adenocarcinomas are locally advanced or metastatic when diagnosed and need to be treated by the combination of surgery and (radio)chemotherapy or by palliative chemotherapy.
\end{abstract}

(C) 2013 S. Karger AG, Basel

\section{Introduction}

Despite recent advances in cancer therapy, pancreatic ductal adenocarcinoma remains one of the most aggressive tumor entities and is among the most frequent causes of tumorassociated deaths in the European Union and the United States [1, 2]. Whereas the overall 5 -year survival rate is around 5\%, surgery is the only potential hope of a cure. The 5-year survival increases to $>20 \%$ in resected patients who undergo multimodal therapy $[3,4]$. Whilst pancreatic surgery has developed and become a relatively safe intervention in specialized centers, complete tumor resection combined with advantageous tumor characteristics have been demonstrated to be the most critical parameters to achieve long-term survival [5-7].

Current guidelines differentiate between resectable, borderline resectable, locally advanced unresectable and metastatic pancreatic cancer [8]. Surgery embedded in a multimodal setting is the cornerstone in the therapy of resectable and borderline resectable disease. Although limited comparative data are available, there is some evidence from smaller randomized controlled trials that resection of locally invasive pancreatic cancer, which included American Joint Committee of Cancer (AJCC)/International Union Against Cancer (UICC) stage IIA and IIB tumors or those invading the porto-mesenteric vein, results in longer survival compared to chemoradiation [9] or palliative gastrobiliary bypass [10]. Early diagnosis of pancreatic cancer combined with correct tumor staging is of utmost importance to apply the adequate multimodal tumor therapy. The present review summarizes the current evidence on the diagnostics, staging and therapy of pancreatic cancer and highlights some areas of remaining controversy. Some parts of the present review have been published previously by the authors, where a more detailed analysis of possible improvements of surgical results for pancreatic cancer and of the therapy of advanced-stage disease is provided $[11,12]$.

\section{Diagnostics}

\section{Imaging}

Small tumor size is one of the most relevant positive predictive factors in pancreatic cancer, and high-quality imaging techniques play a crucial role in the diagnosis of pancreatic tumors. In most cases, tumor diagnosis and resectability is adequately evaluable using one 
cross-sectional imaging study and the current state-of-the-art imaging modality is contrastenhanced multidetector computed tomography (CT) with advanced volumetric processing techniques $[8,13]$. Patients are typically scanned in an arterial and venous phase. The arterial phase shows excellent opacification of the celiac axis and the superior mesenteric artery, whereas the superior mesenteric vein, the portal vein, the splenic vein, and the pancreas itself are well opacified in the venous phase. Likewise, the detection of liver metastasis is optimal in the latter phase. The method of choice in the imaging of pancreatic pathologies is hydro-CT, which involves distension of the stomach and duodenum by administration of 1-1.5 l of water as a negative contrast medium under medically induced hypotension by administration of Buscopan. Magnetic resonance imaging including magnetic resonance cholangiography may be advantageous for the differentiation of cystic pancreatic neoplasms, but does not add information on resectability. Endoscopic ultrasound (EUS) can complement other imaging modalities with valuable staging information and is good in detecting especially smaller lesions. At present, the routine use of endoscopic retrograde cholangiopancreatography or fluorine-18 fluorodeoxyglucose positron emission tomography cannot be recommended [8, 13].

\section{Tumor Biopsy}

In potentially resectable tumors, the necessity for preoperative biopsy of suspected pancreatic cancer is controversial. Positions vary between mandatory histological proof of carcinoma prior to surgical intervention to prevent unnecessary operations and to decrease health care costs [14-16] and the indication of operative exploration even on minor suspicion of malignancy to minimize delay of surgery and to prevent tumor spread by biopsy procedures [17-20]. Unlike resectable tumors, histopathologic confirmation is necessary in patients deemed to have inoperable tumors or those who are medically unsuitable for surgery. In the National Comprehensive Cancer Network (NCCN) guidelines for pancreatic adenocarcinoma, it is strongly recommended that all patients with unresectable pancreatic cancer have cancer confirmation prior to non-surgical treatment [21]. In general, extrapancreatic metastasis should be preferentially targeted by biopsy in case of verified systemic disease, due to easier accessibility, higher cell retrieval and a presumably lower or comparable complication rate $[22,23]$. EUS-guided fine needle aspiration (EUS-FNA) is regarded to be the best modality for obtaining a tissue diagnosis in locoregional disease when needed (e.g. prior to neoadjuvant therapy) $[8,13]$.

Recent meta-analyses demonstrated a pooled sensitivity of EUS-FNA in diagnosing the correct etiology for solid pancreatic mass of $86.8 \%$ and a pooled specificity of $95.8 \%$ [24]. The sensitivity was higher when a $25 \mathrm{G}$ needle system was used as compared to a $22 \mathrm{G}$ needle system [25]. For cystic lesions, FNA accuracy data are much worse. A pooled sensitivity of $54 \%$ was described for cytology and of $63 \%$ for cyst fluid carcinoembryonic antigen [26]. Based on these data, preoperative biopsy cannot be recommended in patients with a curative resectable pancreatic neoplasm. The inaccuracy and high rate of false-negative results of biopsies, the risk of biopsy-induced complications with tumor seeding or delay of surgery, and the lack of evidence that a preoperative biopsy can alter management should discourage the physician from performing preoperative biopsies on these patients [27].

\section{Tumor Staging}

TNM Staging

The TNM classification is used to characterize the local and systemic growth of pancreatic adenocarcinoma. Tumor size and invasion of nearby tissue, lymph node metastasis, and distant metastases have been shown to correlate with the prognosis of the disease. The UICC 
Table 1. TNM staging of pancreatic adenocarcinoma

\section{TNM classification}

$T=$ primary tumor

TX primary tumor cannot be assessed

T0 no evidence of primary tumor

Tis carcinoma in situ

T1 tumor restricted to the pancreas, $\leq 2 \mathrm{~cm}$ in greatest dimension

T2 tumor restricted to the pancreas, $>2 \mathrm{~cm}$ in greatest dimension

T3 tumor extends beyond the pancreas, no involvement of the celiac axis or superior mesenteric artery

T4 tumor affects the celiac axis or the superior mesenteric artery

$N=$ regional lymph node

NX regional lymph nodes cannot be assessed

N0 no regional lymph node metastasis

N1 regional lymph node metastasis

$M=$ distant metastasis

M0 no distant metastasis

M1 distant metastasis

\begin{tabular}{llrl}
\hline UICC staging and survival & & \\
\hline Stages & Resectability & $\begin{array}{l}\text { Median } \\
\text { survival, } \\
\text { months }\end{array}$ & $\begin{array}{l}\text { 5-year } \\
\text { survival, } \\
\%\end{array}$ \\
\hline 0 (Tis, N0, M0) & carcinoma in situ, resectable & NA & NA \\
IA (T1, N0, M0) & localized, resectable & $24-42$ & $31-39$ \\
IB (T2, N0, M0) & localized, resectable & $20-26$ & $22-27$ \\
IIA (T3, N0, M0) & $\begin{array}{l}\text { locally invasive, resectable, eventually borderline } \\
\text { resectable when extended T3 }\end{array}$ & $15-30$ & $16-25$ \\
IIB (T1-3, N1, M0) & $\begin{array}{l}\text { locally invasive, resectable, eventually borderline } \\
\text { resectable when extended T3 }\end{array}$ & $12-21$ & $8-10$ \\
III (T4, any N, M0) & $\begin{array}{l}\text { locally advanced, borderline resectable or unresectable } \\
\text { IV (any T, any N, M1) }\end{array}$ & $11-14$ & $0-7$ \\
\hline
\end{tabular}

Survival data for resected pancreatic adenocarcinoma extracted from [5, 60-62]. NA = Data not available. Table as published by Hartwig et al. [11].

and the AJCC have released a staging system which is based on the TNM classification, with the aim to characterize tumor stages that have a distinguishable prognosis [28, 29]. Table 1 describes the TNM classification and the AJCC/UICC staging system for pancreatic cancer and provides an overview of published stage-specific median survival times and 5-year survival rates. Further prognostic parameters that are not included in the AJCC/UICC staging system include the grade of differentiation of tumor cells, tumor clearance at operative resection margins and perineural or lymphovascular invasion. Since a large variation of the prognosis of patients within the AJCC/UICC tumor stages has been described, prognostic scores and nomograms have been suggested with possible effects on peri- and postoperative decision making $[5,30]$.

\section{Tumor Markers}

Tumor marker-adjusted surgical as well as non-surgical therapy in pancreatic cancer has been proposed by several authors. At present, CA19-9 may qualify best for this purpose due 
to its secretion in about $75-80 \%$ of pancreatic cancer patients. Other tumor markers have failed to be successfully implemented in the clinical routine of pancreatic cancer therapy. Preas well as postresection CA19-9 levels have been demonstrated to contribute valuable information in the prediction of malignancy, resectability and prognosis of pancreatic cancer patients. Resectability and survival rates progressively decrease with increasing CA19-9 levels, with a dismal prognosis in patients with preoperative CA19-9 levels $\geq 1,000 \mathrm{U} / \mathrm{ml}$ or early postoperative increasing levels [31-33]. However, at present it is unclear whether extraordinarily increased CA19-9 indicates otherwise undetected disseminated disease which needs profound diagnostic work-up, or whether neoadjuvant therapy may help identify those patients who might not benefit from radical resection [34]. Likewise, persistently high or increasing postresection CA19-9 levels may select patients who might not benefit from standard adjuvant therapy [32].

\section{Surgery}

Apart from favorable tumor characteristics, complete tumor resection is probably the most relevant prognostic factor in patients with pancreatic cancer. Evidence from randomized, controlled trials investigating surgical vs. non-surgical therapy is limited because studies on this issue are considerably hampered by ethical concerns. However, a multicenter trial comparing resection and chemoradiotherapy for locally invasive resectable pancreatic cancer (AJCC/UICC stages IIA and IIB) demonstrated significantly better outcomes in the surgery group, despite the premature termination of the trial [9]. Likewise, a small randomized study demonstrated longer survival with mono-bloc spleno-pancreatoduodenectomy compared to palliative gastrobiliary bypass in patients with advanced pancreatic cancer and portal-mesenteric venous invasion [10]. The extension of the surgical intervention for pancreatic adenocarcinoma has been a matter of intense controversy. Some of these issues are highlighted in the following sections.

\section{Resectability}

There is wide agreement that localized, non-metastatic pancreatic tumors without involvement of the porto-mesenteric vein and the main visceral arteries (AJCC/UICC tumor stages I and II) are primarily considered resectable (table 1$)[8,13]$. On the contrary, the presence of distant metastases (AJCC/UICC tumor stage IV) is regarded to indicate nonresectable disease and requires chemotherapy as first treatment. Circumferential encasement of the celiac axis, the hepatic artery or the superior mesenteric artery with suspected arterial tumor infiltration (T4 or AJCC/UICC tumor stage III) is also categorized as non-resectable in most cases $[8,13]$. At present, a wide range of definitions is available regarding borderline resectable tumors, and a recent expert consensus statement has undertaken the effort to provide a generally acceptable definition (table 2) [13]. However, with growing experience in vascular surgery, pancreatic surgeons less frequently consider vascular involvement as a criterion for non-resectability (fig. 1). In particular, involvement of the superior mesenteric or portal vein, even in cases with circumferential encasement or occlusion, allows for primary resection and reconstruction by end-to-end anastomosis in most cases in experienced centers as long as a suitable vessel proximal and distal to the area of vessel involvement is present $[35,36]$.

\section{Lymphadenectomy}

Multiple studies including a large, population-based analysis have verified the negative predictive value of lymph node involvement in pancreatic cancer [37]. Both the number of 


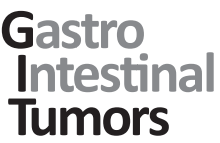

\begin{tabular}{l|l}
\hline \multicolumn{2}{l}{ Gastrointest Tumors 2014;1:41-52 } \\
\hline DOI: $10.1159 / 000354992$ & $\begin{array}{l}\text { C 2013 S. Karger AG, Basel } \\
\text { www.karger.com/gat }\end{array}$ \\
\hline
\end{tabular}

Hartwig et al.: Pancreatic Cancer: Current Options for Diagnosis, Staging and Therapeutic Management

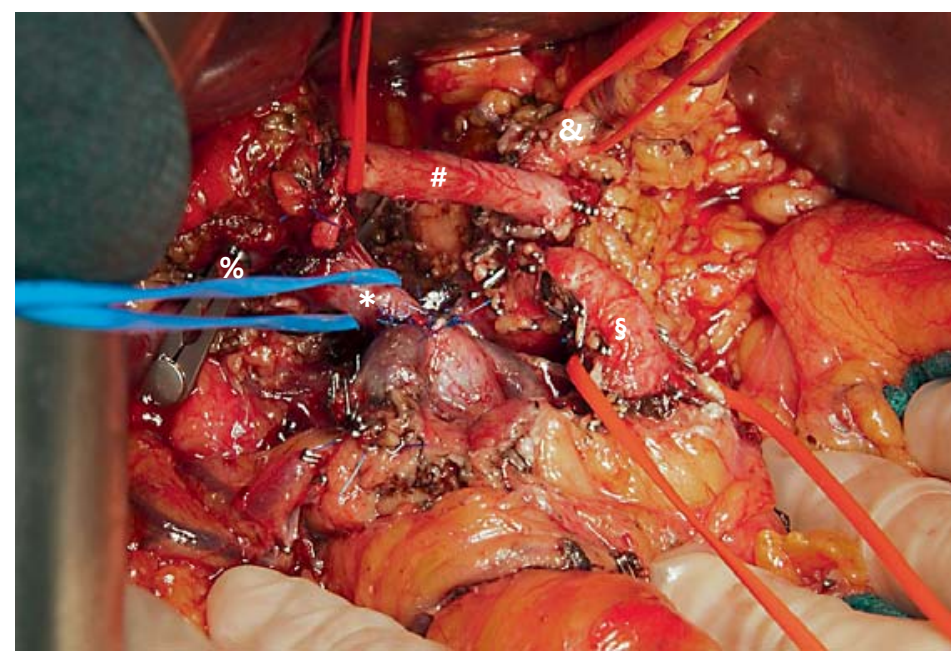

Fig. 1. Intraoperative finding after resection of a borderline resectable pancreatic body tumor. Total pancreatectomy including resection of the transverse mesocolon and extensive dissection of the soft tissue around the superior mesenteric artery and the celiac trunk has been performed. Surgical site prior to reconstruction with hepaticojejunostomy and gastrojejunostomy. \# = Common hepatic artery; $§=$ superior mesenteric artery; \& = left gastric artery; * = porto-mesenteric vein after segmental resection and end-to-end anastomosis; $\%=$ bulldog clamp on the bile duct for temporary occlusion.

Table 2. Resectable and borderline resectable pancreatic cancer according to the consensus statement of the AHPBA/SSO/SSAT [13]

Tumors considered localized and resectable should demonstrate the following:

a No distant metastasis

b No radiographic evidence of SMV and portal vein abutment, distortion, tumor thrombus or venous encasement

c Clear fat planes around the celiac axis, hepatic artery and SMV

Tumors considered borderline resectable include the following:

a No distant metastasis

b Venous involvement of the SMV/portal vein demonstrating tumor abutment with or without impingement and narrowing of the lumen, encasement of the SMV/portal vein but without encasement of the nearby arteries, or short segment venous occlusion resulting from either tumor thrombus or encasement but with suitable vessel proximal and distal to the area of vessel involvement, allowing for safe resection and reconstruction

c Gastroduodenal artery encasement up to the hepatic artery with either short segment encasement or direct abutment of the hepatic artery, without extension to the celiac axis

d Tumor abutment of the superior mesenteric artery not to exceed $180^{\circ}$ of the circumference of the vessel wall

AHPBA = American Hepato-Pancreato-Biliary Association; SSO = Society of Surgical Oncology; SSAT = Society for Surgery of the Alimentary Tract; SMV = superior mesenteric vein.

lymph nodes evaluated in N0 disease and the lymph node ratio in N1 disease were among the most powerful factors associated with survival. With the aim to improve survival, extended lymphadenectomy including retroperitoneal soft tissue clearance has been evaluated in various comparative studies and in four randomized controlled trials. Recent meta-analyses $[38,39]$ did not support the benefit of extended lymphadenectomy on overall survival, but 
instead demonstrated a tendency towards higher rates of delayed gastric emptying. Therefore, standard but not extended lymphadenectomy should be regarded as the procedure of choice in pancreatoduodenectomy. A recent consensus definition of the International Study Group of Pancreatic Surgery (ISGPS) provides a current recommendation for the lymph node stations which should be included in standard lymphadenectomy for both pancreatic head resections and distal pancreatectomies [40].

Vascular and Multivisceral Resections

Pancreatic head and body tumors grow in close proximity to the main visceral vessels, and infiltration of the porto-mesenteric vein and the superior mesenteric artery or the celiac axis is a common clinical finding in locally advanced tumors. Whereas venous infiltration is included within the T3 category according to the TNM grading system, mesenteric artery or celiac axis infiltration is graded a prognostic unfavorable T4 or AJCC/UICC tumor stage III and is in general deemed to be unresectable based on surgical complexity along with poor long-term survival (table 1). Likewise, splenic artery infiltration has been associated with poor survival in pancreatic body and tail cancer. A recent meta-analysis of predominantly retrospective cohort studies confirmed that arterial resection in patients undergoing pancreatectomy was associated with substantial morbidity and mortality and a poor long-term survival rate which, however, was more favorable compared to patients who did not undergo resection for locally advanced pancreatic cancer [41]. Unlike arterial resection, which at present cannot in general be recommended, porto-mesenteric vein resection is a standard procedure at high-volume pancreatic centers. With no randomized controlled trials available, two recent meta-analyses comprising 1,458 and 2,247 patients with pancreatoduodenectomy and pancreatectomy, respectively showed no differences in morbidity, mortality or 5 -year overall survival between patients with venous resection and those without $[35,36]$. These data affirm that experience in vascular surgery is indispensable for a pancreatic surgeon. For locally advanced tumors, multivisceral resections are also very feasible at specialized centers [42, 43]. Long-term results seem comparable to matched standard pancreatectomies, but increased perioperative morbidity demands close postoperative surveillance of patients.

\section{Multimodal Therapy}

\section{Adjuvant Therapy}

Pancreatic cancer is characterized by a high metastatic potential with possibly systemic dissemination early in the course of the disease. Minimal residual disease after pancreatic resection is the rationale for adjuvant therapy. Adjuvant therapy has advanced to such an extent that it now plays an inherent role in pancreatic cancer treatment. The European Study Group of Pancreatic Cancer (ESPAC) was the first to report significantly increased median and 5-year survival rates with adjuvant fluorouracil plus folinic acid after R0/R1 resection compared to surgery alone [44]. This survival benefit was further supported by the composite data from the ESPAC-1 and ESPAC-3 trials [45]. More recently, the CONKO-001 and Asian JSAP-02 trials that evaluated adjuvant gemcitabine vs. observation confirmed a significant increase in disease-free survival, median survival and estimated 5-year overall survival compared to surgery alone $[4,46,47]$. The comparison of adjuvant fluorouracil plus folinic acid vs. gemcitabine did not show any survival differences, but significantly less treatmentrelated serious adverse events with gemcitabine were observed [3]. Similar to pancreatic ductal adenocarcinoma, adjuvant therapy was also effective in resected periampullary adenocarcinomas when multivariate analysis adjusted for prognostic variables [48]. Overall, the 
Hartwig et al.: Pancreatic Cancer: Current Options for Diagnosis, Staging and Therapeutic Management

available evidence from randomized controlled trials clearly shows an improvement of surgical results when adjuvant chemotherapy is added.

Unlike chemotherapy, the benefit of adjuvant chemoradiotherapy or immunochemoradiotherapy in pancreatic cancer remains controversial despite its wide-range use in the United States. Meta-analyses of randomized controlled trials could not identify an overall beneficial effect of adjuvant chemoradiotherapy $[49,50]$. Conflicting results were found in the subgroup of patents with R1 resections $[49,50]$. Similarly, chemoradiotherapy proved more toxic and less effective in locally advanced unresectable pancreatic cancer compared to gemcitabine alone [51]. A recent randomized controlled phase III trial of adjuvant chemoradiotherapy plus interferon $\alpha$ showed similar survival rates but an enormously increased rate of grade 3 or 4 toxicity (85\% of patients) compared to fluorouracil and folinic acid [52]. However, the median survival times of 26.5 and 28.5 months, which are the highest reported for resected pancreatic adenocarcinoma in a randomized controlled setting to date, reflect the promising results which can be achieved by surgery with rather aggressive soft tissue clearance as performed in most patients in that study.

\section{Neoadjuvant Therapy}

The role of neoadjuvant therapy in pancreatic cancer is less well understood, and evidence supporting its benefit originates from phase I/II trials and retrospective analyses. The rationale for neoadjuvant therapy is two-fold. First, locally non-resectable or borderline resectable tumors which infiltrate the superior mesenteric artery and/or the celiac trunk or the porto-mesenteric vein may be downstaged with the aim to make subsequent resection possible. With this intent, irradiation of the local tumor site is the main element of neoadjuvant therapy in order to achieve tumor shrinkage. Second, occult metastatic disease at the time of primary diagnosis may be adequately treated by the chemotherapeutic component of neoadjuvant therapy. By separating progressive from non-progressive disease, neoadjuvant therapy may help identify those patients with favorable tumor biology who may benefit most from resection. Patients with poor tumor biology and disease progression are selected, thereby the morbidity of an unnecessary surgical intervention is avoided.

Systematic reviews and meta-analyses have demonstrated that about a third of tumors initially designated unresectable were resectable after neoadjuvant chemoradiotherapy, with a reduced risk of positive resection margins [53]. There may be a higher risk of perioperative mortality in patients receiving neoadjuvant chemoradiotherapy, but no detrimental effects on the overall survival rate, which is comparable with that of patients who were primarily staged as resectable. However, the quality of currently available data is poor and influenced by patient selection bias, and it is unclear which patients will benefit from neoadjuvant chemoradiotherapy. It is obvious that responders may have a chance of cure after complete resection. In the group of primarily resectable patients, resection and survival rates after neoadjuvant therapy are similar to the ones observed in primarily resected tumors that are treated by adjuvant therapy [53]. Neoadjuvant chemoradiotherapy, which is associated with relevant grade 3-4 toxicity, cannot be considered as standard in primarily resectable patients [8].

The lack of a widely accepted definition of unresectability or borderline resectability is the most significant problem for studies and meta-analyses of neoadjuvant therapy in locally advanced disease. Phase III trials on patients with well-defined locally unresectable or borderline resectable tumors and applying state-of-the-art chemoradiotherapy regimens, possibly consisting of induction chemotherapy and subsequent chemoradiotherapy, are badly needed. The value of neoadjuvant FOLFIRINOX, which is increasingly used after it has proved highly effective in the palliative setting [54], remains to be investigated in controlled trials. 


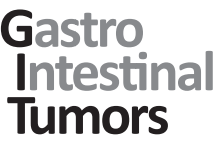

\section{Palliative Therapy}

Palliative chemotherapy is the standard treatment of choice for patients with metastatic pancreatic cancer or for those with locally advanced disease who do not qualify for surgery. As compared to 5-fluorouracil, a modest survival benefit combined with a relevant clinical benefit regarding pain control and Karnofsky performance status have made gemcitabine monotherapy the therapeutic standard for years [55]. Subsequently, meta-analyses and randomized controlled trials have demonstrated a small survival benefit for the combination of gemcitabine with platinum derivates, capecitabine, or the tyrosine kinase inhibitor erlotinib [56-58]. More recently, the combination chemotherapy FOLFIRINOX showed a markedly increased response rate and overall survival compared to gemcitabine monotherapy [54]. Despite an increase in severe adverse effects, a detailed analysis showed that the FOLFIRINOX therapy significantly reduced quality of life impairment [59]. However, the FOLFIRINOX protocol is only a treatment option for a minority of patients who are characterized by good performance status, relatively low bilirubin levels, good bone marrow and renal function, and without a history of significant heart disease. Surgical interventions (e.g. bypass procedures) play a minor role in the palliative setting [12].

\section{Disclosure Statement}

The authors declare that there are no conflicts of interest.

\section{References}

1 Malvezzi M, Bertuccio P, Levi F, La Vecchia C, Negri E: European cancer mortality predictions for the year 2012. Ann Oncol 2012;23:1044-1052.

2 Siegel R, Naishadham D, Jemal A: Cancer statistics, 2012. CA Cancer J Clin 2012;62:10-29.

-3 Neoptolemos JP, Stocken DD, Bassi C, Ghaneh P, Cunningham D, Goldstein D, Padbury R, Moore MJ, Gallinger S, Mariette C, Wente MN, Izbicki JR, Friess H, Lerch MM, Dervenis C, Olah A, Butturini G, Doi R, Lind PA, Smith D, Valle JW, Palmer DH, Buckels JA, Thompson J, McKay CJ, Rawcliffe CL, Büchler MW: Adjuvant chemotherapy with fluorouracil plus folinic acid vs gemcitabine following pancreatic cancer resection: a randomized controlled trial. JAMA 2010;304:1073-1081.

-4 Oettle H, Post S, Neuhaus P, Gellert K, Langrehr J, Ridwelski K, Schramm H, Fahlke J, Zuelke C, Burkart C, Gutberlet K, Kettner E, Schmalenberg H, Weigang-Koehler K, Bechstein WO, Niedergethmann M, Schmidt-Wolf I, Roll L, Doerken B, Riess H: Adjuvant chemotherapy with gemcitabine vs observation in patients undergoing curative-intent resection of pancreatic cancer: a randomized controlled trial. JAMA 2007;297:267-277.

5 Hartwig W, Hackert T, Hinz U, Gluth A, Bergmann F, Strobel O, Büchler MW, Werner J: Pancreatic cancer surgery in the new millennium: better prediction of outcome. Ann Surg 2011;254:311-319.

6 Mayo SC, Nathan H, Cameron JL, Olino K, Edil BH, Herman JM, Hirose K, Schulick RD, Choti MA, Wolfgang CL, Pawlik TM: Conditional survival in patients with pancreatic ductal adenocarcinoma resected with curative intent. Cancer 2012;118:2674-2681.

7 Konstantinidis IT, Warshaw AL, Allen JN, Blaszkowsky LS, Fernandez-del Castillo C, Deshpande V, Hong TS, Kwak EL, Lauwers GY, Ryan DP, Wargo JA, Lillemoe KD, Ferrone CR: Pancreatic ductal adenocarcinoma: Is there a survival difference for R1 resections versus locally advanced unresectable tumors? What is a 'true' R0 resection? Ann Surg 2013;257:731-736.

-8 Tempero MA, Arnoletti JP, Behrman SW, Ben Josef E, Benson AB III, Casper ES, Cohen SJ, Czito B, Ellenhorn JD, Hawkins WG, Herman J, Hoffman JP, Ko A, Komanduri S, Koong A, Ma WW, Malafa MP, Merchant NB, Mulvihill SJ, Muscarella P, Nakakura EK, Obando J, Pitman MB, Sasson AR, Tally A, Thayer SP, Whiting S, Wolff RA, Wolpin BM, Freedman-Cass DA, Shead DA; National Comprehensive Cancer Networks: Pancreatic Adenocarcinoma, version 2.2012: featured updates to the NCCN Guidelines. J Natl Compr Canc Netw 2012;10:703-713. Imamura M, Doi R, Imaizumi T, Funakoshi A, Wakasugi H, Sunamura M, Ogata Y, Hishinuma S, Asano T, Aikou T, Hosotani R, Maetani S: A randomized multicenter trial comparing resection and radiochemotherapy for resectable locally invasive pancreatic cancer. Surgery 2004;136:1003-1011. 
10 Lygidakis NJ, Singh G, Bardaxoglou E, Dedemadi G, Sgourakis G, Nestoridis J, Malliotakis A, Pedonomou M, Solomou EK, Safioleas M, Alamani M, Grigorakos L, Merikas EM: Mono-bloc total spleno-pancreaticoduodenectomy for pancreatic head carcinoma with portal-mesenteric venous invasion. A prospective randomized study. Hepatogastroenterology 2004;51:427-433.

11 Hartwig W, Werner J, Jäger D, Debus J, Büchler MW: Improvement of surgical results for pancreatic cancer. Lancet Oncol 2013, in press.

12 Werner J, Combs SE, Springfeld C, Hartwig W, Hackert T, Buchler MW: Advanced-stage pancreatic cancer: therapy options. Nat Rev Clin Oncol 2013;10:323-333.

-13 Callery MP, Chang KJ, Fishman EK, Talamonti MS, William TL, Linehan DC: Pretreatment assessment of resectable and borderline resectable pancreatic cancer: expert consensus statement. Ann Surg Oncol 2009; 16:1727-1733.

14 Harewood GC, Wiersema MJ: A cost analysis of endoscopic ultrasound in the evaluation of pancreatic head adenocarcinoma. Am J Gastroenterol 2001;96:2651-2656.

15 Chen VK, Arguedas MR, Kilgore ML, Eloubeidi MA: A cost-minimization analysis of alternative strategies in diagnosing pancreatic cancer. Am J Gastroenterol 2004;99:2223-2234.

-16 Di Stasi M, Lencioni R, Solmi L, Magnolfi F, Caturelli E, De Sio I, Salmi A, Buscarini L: Ultrasound-guided fine needle biopsy of pancreatic masses: results of a multicenter study. Am J Gastroenterol 1998;93:1329-1333.

17 Tillou A, Schwartz MR, Jordan PHJ: Percutaneous needle biopsy of the pancreas: when should it be performed? World J Surg 1996;20:283-286.

18 Nakamura R, Machado R, Amikura K, Ruebner B, Frey CF: Role of fine needle aspiration cytology and endoscopic biopsy in the preoperative assessment of pancreatic and peripancreatic malignancies. Int J Pancreatol 1994;16:17-21.

19 Kahl S, Malfertheiner P: Role of endoscopic ultrasound in the diagnosis of patients with solid pancreatic masses. Dig Dis 2004;22:26-31.

20 Cahn M, Chang K, Nguyen P, Butler J: Impact of endoscopic ultrasound with fine-needle aspiration on the surgical management of pancreatic cancer. Am J Surg 1996;172:470-472.

21 National Comprehensive Cancer Network: NCCN clinical practice guidelines in oncology. Pancreatic adenocarcinoma. National Comprehensive Cancer Network, 2006.

22 Phillips VM, Knopf DR, Bernardino ME: Percutaneous hepatic biopsy in suspected pancreatic carcinoma. J Comput Tomogr 1984;8:307-310.

23 Matsubara J, Okusaka T, Morizane C, Ikeda M, Ueno H: Ultrasound-guided percutaneous pancreatic tumor biopsy in pancreatic cancer: a comparison with metastatic liver tumor biopsy, including sensitivity, specificity, and complications. J Gastroenterol 2008;43:225-232.

24 Puli SR, Bechtold ML, Buxbaum JL, Eloubeidi MA: How good is endoscopic ultrasound-guided fine-needle aspiration in diagnosing the correct etiology for a solid pancreatic mass?: A meta-analysis and systematic review. Pancreas 2013;42:20-26.

25 Madhoun MF, Wani SB, Rastogi A, Early D, Gaddam S, Tierney WM, Maple JT: The diagnostic accuracy of 22-gauge and 25-gauge needles in endoscopic ultrasound-guided fine needle aspiration of solid pancreatic lesions: a meta-analysis. Endoscopy 2013;45:86-92.

-26 Thornton GD, McPhail MJ, Nayagam S, Hewitt MJ, Vlavianos P, Monahan KJ: Endoscopic ultrasound guided fine needle aspiration for the diagnosis of pancreatic cystic neoplasms: a meta-analysis. Pancreatology 2013;13: 48-57.

27 Hartwig W, Schneider L, Diener MK, Bergmann F, Büchler MW, Werner J: Preoperative tissue diagnosis for tumours of the pancreas. Br J Surg 2009;96:5-20.

28 Sobin LH, Gospodarowicz MK, Wittekind C (eds): TNM Classification of Malignant Tumours, ed 7. New York, Wiley-Blackwell, 2009.

29 Edge SB, Byrd DR, Compton CC, Fritz AG, Greene FL, Trotti A (eds): AJCC Cancer Staging Manual. New York, Springer, 2010.

-30 Brennan MF, Kattan MW, Klimstra D, Conlon K: Prognostic nomogram for patients undergoing resection for adenocarcinoma of the pancreas. Ann Surg 2004;240:293-298.

-31 Berger AC, Garcia M Jr, Hoffman JP, Regine WF, Abrams RA, Safran H, Konski A, Benson AB III, MacDonald J, Willett CG: Postresection CA 19-9 predicts overall survival in patients with pancreatic cancer treated with adjuvant chemoradiation: a prospective validation by RTOG 9704. J Clin Oncol 2008;26:5918-5922.

-32 Humphris JL, Chang DK, Johns AL, Scarlett CJ, Pajic M, Jones MD, Colvin EK, Nagrial A, Chin VT, Chantrill LA, Samra JS, Gill AJ, Kench JG, Merrett ND, Das A, Musgrove EA, Sutherland RL, Biankin AV: The prognostic and predictive value of serum CA19.9 in pancreatic cancer. Ann Oncol 2012;23:1713-1722.

-33 Hartwig W, Strobel O, Hinz U, Fritz S, Hackert T, Roth C, Büchler MW, Werner J: CA19-9 in potentially resectable pancreatic cancer: perspective to adjust surgical and perioperative therapy. Ann Surg Oncol 2013;20:21882196.

-34 Katz MH, Varadhachary GR, Fleming JB, Wolff RA, Lee JE, Pisters PW, Vauthey JN, Abdalla EK, Sun CC, Wang H, Crane CH, Lee JH, Tamm EP, Abbruzzese JL, Evans DB: Serum CA 19-9 as a marker of resectability and survival in patients with potentially resectable pancreatic cancer treated with neoadjuvant chemoradiation. Ann Surg Oncol 2010;17:1794-1801.

35 Chua TC, Saxena A: Extended pancreaticoduodenectomy with vascular resection for pancreatic cancer: a systematic review. J Gastrointest Surg 2010;14:1442-1452. 
-36 Zhou Y, Zhang Z, Liu Y, Li B, Xu D: Pancreatectomy combined with superior mesenteric vein-portal vein resection for pancreatic cancer: a meta-analysis. World J Surg 2012;36:884-891.

-37 Slidell MB, Chang DC, Cameron JL, Wolfgang C, Herman JM, Schulick RD, Choti MA, Pawlik TM: Impact of total lymph node count and lymph node ratio on staging and survival after pancreatectomy for pancreatic adenocarcinoma: a large, population-based analysis. Ann Surg Oncol 2008;15:165-174.

-38 Michalski CW, Kleeff J, Wente MN, Diener MK, Büchler MW, Friess H: Systematic review and meta-analysis of standard and extended lymphadenectomy in pancreaticoduodenectomy for pancreatic cancer. Br J Surg 2007; 94:265-273.

-39 Iqbal N, Lovegrove RE, Tilney HS, Abraham AT, Bhattacharya S, Tekkis PP, Kocher HM: A comparison of pancreaticoduodenectomy with extended pancreaticoduodenectomy: a meta-analysis of 1909 patients. Eur J Surg Oncol 2009;35:79-86.

40 Tol J, Gouma DJ, Bassi C, et al: Definition of a standard lymphadenectomy in surgery for pancreatic ductal adenocarcinoma. A consensus statement by the International Study Group on Pancreatic Surgery (ISGPS). Surgery 2013, submitted.

41 Mollberg N, Rahbari NN, Koch M, Hartwig W, Hoeger Y, Büchler MW, Weitz J: Arterial resection during pancreatectomy for pancreatic cancer: a systematic review and meta-analysis. Ann Surg 2011;254:882-893.

-42 Hartwig W, Hackert T, Hinz U, Hassenpflug M, Strobel 0, Büchler MW, Werner J: Multivisceral resection for pancreatic malignancies: risk-analysis and long-term outcome. Ann Surg 2009;250:81-87.

-43 Burdelski CM, Reeh M, Bogoevski D, Gebauer F, Tachezy M, Vashist YK, Cataldegirmen G, Yekebas E, Izbicki JR, Bockhorn M: Multivisceral resections in pancreatic cancer: identification of risk factors. World J Surg 2011; 35:2756-2763.

44 Neoptolemos JP, Dunn JA, Stocken DD, Almond J, Link K, Beger H, Bassi C, Falconi M, Pederzoli P, Dervenis C, Fernandez-Cruz L, Lacaine F, Pap A, Spooner D, Kerr DJ, Friess H, Büchler MW: Adjuvant chemoradiotherapy and chemotherapy in resectable pancreatic cancer: a randomised controlled trial. Lancet 2001;358:15761585.

45 Neoptolemos JP, Stocken DD, Tudur SC, Bassi C, Ghaneh P, Owen E, Moore M, Padbury R, Doi R, Smith D, Büchler MW: Adjuvant 5-fluorouracil and folinic acid vs observation for pancreatic cancer: composite data from the ESPAC-1 and -3(v1) trials. Br J Cancer 2009;100:246-250.

46 Ueno H, Kosuge T, Matsuyama Y, Yamamoto J, Nakao A, Egawa S, Doi R, Monden M, Hatori T, Tanaka M, Shimada M, Kanemitsu K: A randomised phase III trial comparing gemcitabine with surgery-only in patients with resected pancreatic cancer: Japanese Study Group of Adjuvant Therapy for Pancreatic Cancer. Br J Cancer 2009;101:908-915.

47 Neuhaus P, Riess H, Post S, Gellert K, Ridwelski K, Schramm H, Zuelke C, Fahlke J, Langrehr J, Oettle H: CONKO001: final results of the randomized, prospective, multicenter phase III trial of adjuvant chemotherapy with gemcitabine versus observation in patients with resected pancreatic cancer (PC). ASCO annual meeting proceedings (post-meeting edition). J Clin Oncol 2008;26(suppl 15).

-48 Neoptolemos JP, Moore MJ, Cox TF, Valle JW, Palmer DH, McDonald AC, Carter R, Tebbutt NC, Dervenis C, Smith D, Glimelius B, Charnley RM, Lacaine F, Scarfe AG, Middleton MR, Anthoney A, Ghaneh P, Halloran CM, Lerch MM, Olah A, Rawcliffe CL, Verbeke CS, Campbell F, Büchler MW: Effect of adjuvant chemotherapy with fluorouracil plus folinic acid or gemcitabine vs observation on survival in patients with resected periampullary adenocarcinoma: the ESPAC-3 periampullary cancer randomized trial. JAMA 2012;308:147-156.

49 Stocken DD, Büchler MW, Dervenis C, Bassi C, Jeekel H, Klinkenbijl JH, Bakkevold KE, Takada T, Amano H, Neoptolemos JP: Meta-analysis of randomised adjuvant therapy trials for pancreatic cancer. Br J Cancer 2005; 92:1372-1381.

-50 Butturini G, Stocken DD, Wente MN, Jeekel H, Klinkenbijl JH, Bakkevold KE, Takada T, Amano H, Dervenis C, Bassi C, Büchler MW, Neoptolemos JP: Influence of resection margins and treatment on survival in patients with pancreatic cancer: meta-analysis of randomized controlled trials. Arch Surg 2008;143:75-83.

-51 Chauffert B, Mornex F, Bonnetain F, Rougier P, Mariette C, Bouche O, Bosset JF, Aparicio T, Mineur L, Azzedine A, Hammel P, Butel J, Stremsdoerfer N, Maingon P, Bedenne L: Phase III trial comparing intensive induction chemoradiotherapy (60 Gy, infusional 5-FU and intermittent cisplatin) followed by maintenance gemcitabine with gemcitabine alone for locally advanced unresectable pancreatic cancer. Definitive results of the 2000-01 FFCD/SFRO study. Ann Oncol 2008;19:1592-1599.

-52 Schmidt J, Abel U, Debus J, Harig S, Hoffmann K, Herrmann T, Bartsch D, Klein J, Mansmann U, Jäger D, Capussotti L, Kunz R, Büchler MW: Open-label, multicenter, randomized phase III trial of adjuvant chemoradiation plus interferon alfa-2b versus fluorouracil and folinic acid for patients with resected pancreatic adenocarcinoma. J Clin Oncol 2012;30:4077-4083.

53 Gillen S, Schuster T, Meyer Zum Büschenfelde C, Friess H, Kleeff J: Preoperative/neoadjuvant therapy in pancreatic cancer: a systematic review and meta-analysis of response and resection percentages. PLoS Med 2010; 7:e1000267.

54 Conroy T, Desseigne F, Ychou M, Bouché O, Guimbaud R, Bécouarn Y, Adenis A, Raoul JL, Gourgou-Bourgade $\mathrm{S}$, de la Fouchardière C, Bennouna J, Bachet JB, Khemissa-Akouz F, Péré-Vergé D, Delbaldo C, Assenat E, Chauffert B, Michel P, Montoto-Grillot C, Ducreux M: FOLFIRINOX versus gemcitabine for metastatic pancreatic cancer. N Engl J Med 2011;364:1817-1825. 
Burris HA III, Moore MJ, Andersen J, Green MR, Rothenberg ML, Modiano MR, Cripps MC, Portenoy RK, Storniolo AM, Tarassoff P, Nelson R, Dorr FA, Stephens CD, Von Hoff DD: Improvements in survival and clinical benefit with gemcitabine as first-line therapy for patients with advanced pancreas cancer: a randomized trial. J Clin Oncol 1997;15:2403-2413.

-56 Heinemann V, Boeck S, Hinke A, Labianca R, Louvet C: Meta-analysis of randomized trials: evaluation of benefit from gemcitabine-based combination chemotherapy applied in advanced pancreatic cancer. BMC Cancer 2008;8:82.

57 Cunningham D, Chau I, Stocken DD, Valle JW, Smith D, Steward W, Harper PG, Dunn J, Tudur-Smith C, West J, Falk S, Crellin A, Adab F, Thompson J, Leonard P, Ostrowski J, Eatock M, Scheithauer W, Herrmann R, Neoptolemos JP: Phase III randomized comparison of gemcitabine versus gemcitabine plus capecitabine in patients with advanced pancreatic cancer. J Clin Oncol 2009;27:5513-5518.

-58 Moore MJ, Goldstein D, Hamm J, Figer A, Hecht JR, Gallinger S, Au HJ, Murawa P, Walde D, Wolff RA, Campos D, Lim R, Ding K, Clark G, Voskoglou-Nomikos T, Ptasynski M, Parulekar W: Erlotinib plus gemcitabine compared with gemcitabine alone in patients with advanced pancreatic cancer: a phase III trial of the National Cancer Institute of Canada Clinical Trials Group. J Clin Oncol 2007;25:1960-1966.

59 Gourgou-Bourgade S, Bascoul-Mollevi C, Desseigne F, Ychou M, Bouche O, Guimbaud R, Becouarn Y, Adenis A, Raoul JL, Boige V, Berille J, Conroy T: Impact of FOLFIRINOX compared with gemcitabine on quality of life in patients with metastatic pancreatic cancer: results from the PRODIGE 4/ACCORD 11 randomized trial. J Clin Oncol 2013;31:23-29.

-60 Isaji S, Kawarada Y, Uemoto S: Classification of pancreatic cancer: comparison of Japanese and UICC classifications. Pancreas 2004;28:231-234.

61 Bilimoria KY, Bentrem DJ, Ko CY, Ritchey J, Stewart AK, Winchester DP, Talamonti MS: Validation of the 6th edition AJCC Pancreatic Cancer Staging System: report from the National Cancer Database. Cancer 2007;110: 738-744.

62 Wasif N, Bentrem DJ, Farrell JJ, Ko CY, Hines OJ, Reber HA, Tomlinson JS: Invasive intraductal papillary mucinous neoplasm versus sporadic pancreatic adenocarcinoma: a stage-matched comparison of outcomes. Cancer 2010;116:3369-3377. 